\title{
Espejos del tiempo ou tempo dos espelhos? Cochochi, El Violin e Corazón del tiempo: a nova saga do cinema mexicano indígena
}

\author{
Juliano Gonçalves da Silvar \\ Fundação Universidade Regional de Blumenau
}

Resumo: Neste artigo partindo de uma perspectiva de uma antropologia do cinema ainda em construção, analiso como o personagem indígena é construído em alguns filmes de ficção recentes do cinema mexicano, num esforço de descolonização dos imaginários culturais globais e revisão do eurocentrismo. Isso será feito através de uma leitura das suas representações e dos imaginários deles resultantes. Desvelando esses imaginários fílmicos e suas encenações através da mise en scéne, pretendo constituir uma ideia mais ampla sobre quem são esses personagens indígenas e os seus mundos "nativos" que o cinema recente mexicano tem revelado para o mundo.

Palavras-chave: antropologia do cinema; cinema latino-americano; descolonização; filmes de ficção; índios no cinema.

${ }^{1}$ Graduado em Ciências Sociais pela Universidade Federal de Santa Catarina (1997) e mestre em Multimeios pela Universidade Estadual de Campinas (2002). Vinculado ao Departamento de Ciências Sociais no Centro de Ciências Sociais e da Comunicação da FURB. Membro do GRAPPA - Grupo de Análises de Políticas e Poéticas Audiovisuais. 


\title{
Espejos del tiempo or mirrors of time? Cochochi, El Violin and Corazón del tiempo: the new saga of the indigenous Mexican cinema
}

\begin{abstract}
In this article starting from a perspective of an anthropology of cinema under construction, I analyze how the indigenous character is built in some recent fiction films of Mexican cinema in an effort to decolonization of global cultural imaginary and Eurocentrism review. This will be done through a reading of their representations and the imaginary stemming. Unveiling these filmic imaginary and their scenarios through the mise en scéne, I intend to provide a broader idea about who these indigenous characters and their "natives" worlds that the recent Mexican cinema has revealed to the world.

Keywords: anthropology of cinema; Latin American cinema; decolonization; fiction films; indians in cinema.

\section{Espejos del tiempo o espejos de tiempo? Cochochi, El Violín y Corazón del tiempo: la nueva saga del cine mexicano indígena}

Resúmen: En este artículo a partir de una perspectiva de una antropología de cine en construcción, analizo cómo se construye el carácter indígena en algunas películas de ficción recientes del cine mexicano en un esfuerzo por la descolonización de opinión imaginario y eurocentrismo cultural global. Esto se hará a través de una lectura de sus representaciones y lo imaginario derivado. Revelando estos imaginario fílmicos y sus escenarios a través de la mise en scéne, tengo la intención de proporcionar una idea más amplia sobre quiénes son estos personajes indígenas y sus mundos "nativos" que el reciente cine mexicano ha revelado al mundo.

Palabras clave: antropología de cine; cine latinoamericano; descolonización; películas de ficción; indios en el cine. 
Neste artigo realizei uma análise fílmica de três filmes que identifico como constituindo uma nova saga do cinema indígena mexicano, entendendo por isso, o fato desses filmes possuírem características específicas, que rompem com uma fase anterior deste cinema. Tentando se aproximar da construção de um olhar diferenciado sobre as sociedades indígenas mexicanas, nos sensibilizando para uma nova linguagem que traduz essas realidades e as reinterpretam, com elementos próprios dessas culturas e suas visões de mundo, esse cinema nos apresenta as diferentes possibilidades, de ser, suas resistências milenares e atuais frente a conjunturas adversas. Assim registra o seu florescer e sobreviver fílmico seja dentro de estratégias tradicionais que reinterpretem o campo das possibilidades existenciais desses grupos, seja em suas especificidades culturais, seja diante de uma globalidade mundializante que tenta universalizá-los, homogeneizá-los e igualá-los dentro de suas coletividades únicas, culturalmente vivas e pulsantes. Trata-se de um cinema que pergunta e caminha numa direção de recolocar indagações e dúvidas aos seus expectadores, saindo do modelo tradicional hollywoodiano e dos grandes estúdios de produção industrial cinematográficos, trazendo possibilidades de identificação e compartilhamento de experiências que constroem uma outra alteridade e quem sabe "um outro mundo, onde caibam muitos mundos". Isto em outras palavras poderia ser dito como uma posição que busque contribuir para uma descolonização do imaginário e da cultura global, e sobre um ponto de vista multiculturalista, pode ser relativizado sobre muitos aspectos, permitindo:

\begin{abstract}
o entendimento da história do mundo e da vida social contemporânea a partir da perspectiva da igualdade fundamental dos povos em seu potencial, importância e direitos. O multiculturalismo descoloniza as representações não apenas quanto aos artefatos culturais - cânones literários, exibições em museus, filmes - mas principalmente quanto às relações de poder entre diferentes comunidades. (STAM, 2016: 26)
\end{abstract}

Sobre a história do cinema mexicano Peter B. Schumann, em seu livro Historia del cine latino-americano (1987), faz um extenso percurso em sua história do cinema latino americano, eu por outro lado me deterei no artigo no que identifiquei acima como a nova saga do cinema indígena mexicano. Nele irei analisar os filmes: Cochochi ${ }^{2}$ (CÁRDENAS, 2007) onde o autor descreve em rarámuri (língua dos Tahaumaras) o cotidiano de crianças indígenas ao levarem remédios para seu avô doente; El Violin3 (VARGAS, 2006) com o dilema entre a música, a revolução e a resistência atemporal que pode ser em qualquer grupo indígena da América Latina e Corazón del tiempo 4 (CÓRTEZ,

${ }^{2}$ Cochochi. Diretor/roteiro/música e fotografia: Israel Cárdenas, Laura Amelia Guzmán. Financiamento: México / Reino Unido / Canadá. Produtor: Diego Luna. Atores: Evaristo Lerma Batista, Luis Antonio Lerma Batista. Ano/duração: 2007. 87 minutos. Filmado em: San Ignacio, cidade no Valle Okochochi, Sierra Tarahumara, Chihuahua. Linguagem: Rarámuri e Espanhol (Justificar nota de rodapé e manter padronização).

3 El Volin. Diretor/roteiro: Francisco Vargas. Fotografia: Martín Boege, Oscar Hijuelos. Música: Armando Rosas, Cuauhtémoc Tavira. Ano/duração: 2006. 98 minutos. Filmado em: Vila rural. Linguagem: Espanhol. Disponível em: http://www.youtube.com/watch?v=EUTG-3R19ec (Justificar nota de rodapé e manter padronização).

4 Corazón del Tiempo - uma jornada no coração da resistência zapatista. Diretor: Alberto Córtez. Roteiro: Hermam Bellinghausen e Alberto Córtez. Música: Descember Bueno, Kelvis Ochoa. Fotografia: Marc Bellver. Ano/duração: 2008. 87 minutos. Filmado em: Esperanza de San Pedro, Chiapas. Linguagem: Espanhol. Disponível em: http://www.youtube.com/watch?v=M48F9gcvCPE. 
2008), buscando dar imagem e vida aos que vivem nas sombras e nas comunidades zapatistas.

O cinema vem sendo objeto de diferentes leituras e abordagens na atualidade. Dentre estas, alguns autores vêm trabalhando com a ideia do cinema como "campo" no sentido antropológico do termo. Tomando como referência a dissertação de mestrado de Rose Satiko Hikiji Imagem-violência. Mimesis e reflexividade em alguns filmes recentes (1998), podemos identificar alguns autores que se aproximaram dessa perspectiva.

Um dos primeiros que desenvolveu uma pesquisa interessante dentro do paradigma antropológico foi John $\mathrm{H}$. Weakland (1953) que via os filmes ficcionais como documentos culturais que possibilitariam semelhanças na comparação com mitos e ritos.

\begin{abstract}
Ao projetar imagens estruturadas do comportamento humano, interação social e da natureza do mundo, filmes ficcionais nas sociedades contemporâneos são análogos em natureza e significância cultural, as histórias, mitos, rituais e cerimônias em sociedades primitivas. (WEAKLAND apud HIKIJII, 1998: 24).
\end{abstract}

Esta correspondência possibilitaria a construção de uma ponte entre a ficção e a realidade, não as confundindo, tendo mitos e filmes os seguintes pontos em comum: "ambos projetam imagens estruturadas do comportamento humano, da interação social e da natureza do mundo", (HIKIJI, 1998: 24-25) sem serem realistas.

Sigfreud Krackauer em sua obra De Caligari a Hitler (1947) afirma, "que os filmes "refletem" dispositivos psicológico de uma nação, por serem resultado de um esforço coletivo e destinados a multidões" (HIKIJI, 1998: 28). Edgar Morin, a partir de seu livro Cinema ou o homem imaginário (1956), traduzido para o português em 1970, focando os processos do cinema e suas relações com o espectador, considera-o a partir do "mito, sonho e imaginário" (HIKIJI, 1998: 28).

Nos anos oitenta se muda a abordagem da antropologia ao cinema: este passa a ser objeto e elemento para o fazer antropológico. George Marcus, em 1994, propõe a passagem de princípios da escrita cinematográfica para a etnográfica. O Cinema é também equacionado por Robert Stam como já foi anteriormente citado, enquanto rito de passagem, as representações étnicas são assim pautadas, dedicando-se a pensar como o outro não norte americano e branco foi e é representado nos filmes Hollywoodianos 5 .

Massimo Canevacci em seu livro Antropologia da Comunicação Visual (1990) reitera a proposta de Clifford Geertz só que para o cinema, de descrição e interpretação dos filmes como um texto (HIKIJI, 1998: 31). Esta necessidade antropológica de análises dos filmes, segundo o autor, deve-se ao cinema ser um subproduto interno as novas ideologias, com necessidades de reflexões globais e radicais.

Nesta chave retomamos o trabalho de Stam (2007) e sua crítica ao pensamento eurocêntrico na mídia e no cinema, conformando parte deste establishment. Para ele, na possibilidade da análise da "imagem" de um grupo social, devem ser levadas em consideração as dimensões especialmente cinematográficas dos filmes, perguntando: Qual o espaço que os representantes

5 Sua análise revela que o negro, o latino americano e o ameríndio no cinema estão marcados por estereótipos. Com relação aos personagens negros são destacados os papéis estereotipados e estigmatizantes de ignorância, servilidade, hipersexualização e não diferentemente são tratados os personagens latinos, como bandidos, prostitutas mestiças e grudentos. Sempre partindo da premissa de que "quanto mais escuro, pior o personagem" (HIKIJI, 1998: 33). 
dos grupos de negros, índios, latinos ocupam na tela? Qual a sua visibilidade, em primeiro plano ou distanciado? Por quanto tempo aparecem? Como são caracterizados os personagens? Aproximam ou distanciam os espectadores? A linguagem do corpo expressa o que? A sonoplastia é adequada à caracterização do grupo?

Com base nestas referências podemos afirmar que diversos aspectos metodológicos já vêm sendo trabalhados antropologicamente e estarei tomando estes pressupostos como referências na busca de uma nova análise dos filmes, que amplie os modelos tradicionais. Neste percurso além de descrever cortes, enquadramentos e demais pontuações técnicas de leitura filmográfica, procurase amplia-la em busca de uma análise fílmica etnográfica, relacionando-a com a possibilidade de uma "descrição densa" e dialógica com o próprio contexto fílmico. Assim, busco construir uma etnografia do filme, considerando-o como um campo onde realizarei as incursões em busca do registro mais amplo do possível "nativo" e os contextos de suas relações. Partindo-se dessa concepção analisaremos como o personagem indígena é construído nos filmes anteriormente citados. A análise será feita tomando como foco uma leitura fílmica das suas representações ${ }^{6}$ e dos imaginários ${ }^{7}$ construídos, deles resultantes. Desvelando esses imaginários fílmicos e suas encenações através das mise-en-scènes ${ }^{8}$, pretendo constituir uma ideia mais ampla sobre este personagem indígena que o cinema recente mexicano tem revelado para o mundo.

O ator mexicano Diego Luna9 produtor do filme Cochochi em uma entrevista dada ao Festival do Rio em 2007, no Rio de Janeiro compara, o cinema mexicano ao cinema brasileiro. Segundo a sua opinião eles seriam muito semelhantes, apesar do cinema brasileiro ser mais organizado, mas:

\begin{abstract}
continua sendo um cinema de urgência, um cinema cujo valor máximo está na história. Seu valor não é o valor da produção. O valor dos nossos filmes está na história, na honestidade e no poder que tem a história quando alguém a escuta. Nisso nos parecemos muito, pois fazemos um tipo de cinema muito mais inteligente, que celebra um ponto de vista, que fala sobre o mundo pessoal de alguém. É um cinema muito mais poderoso, em todos os sentidos. Os filmes de sucesso que temos feito fazem sucesso porque são grandes filmes, não pela quantidade de dinheiro que há por trás da produção.
\end{abstract}

Buscando analisar estes "grandes filmes" como nos fala Diego Luna e como se é construído o olhar para com os indígenas nesta filmografia, traremos cada filme a cena.

\footnotetext{
${ }^{6}$ O conceito de representação será utilizado com base na discussão que Louis Marin (1994: 255) faz no seu texto Mimésis et discription: "représenter signifie se présenter representant quelque chose et toute représentation, tout signe ou procès représentationnel comprend une double dimension - dimension réflexive, se présenter; dimension transitive, représenter quelque chose".

7 O imaginário e as imagens a ele associadas expressam significados que se referem ao modo como nossa sociedade constrói o que poderíamos chamar de cosmologias contemporâneas, através de metáforas e alegorias.

${ }^{8}$ Estou entendendo por mise-en-scène o que se coloca em cena ou a realidade construída pelo filme. A encenação por outro lado, mais relacionada a performance, seria a decomposição de cada um dos personagens em suas representações e os sentidos dela refletidos em comparação aos contextos sociais mais amplos e extra campos fílmicos.

${ }_{9}$ Diego Luna Alexander (Cidade do México, 29 de dezembro de 1979) é um ator de televisão, teatro e cinema. É filho do cenógrafo Alejandro Luna e da falecida figurinista Fiona Alexander. Disponível em: http://www.yasni.com.br/ext.php?url=http\%3A\%2F\%2Fpt.wikipedia.org\%2Fwiki\%2FDiego_Luna\&name=Diego+Aleja ndro+Luna\&cat $=$ celebrity\&showads $=1$
} 


\section{Começos e tropeços: entre a escola e a vida}

Cochochi é um filme que narra a vida e dúvidas de dois meninos indígenas. Ele se passa no limiar da vida de uma criança indígena em idade escolar, no México de hoje, frente a uma educação bilíngue e que vão depois de formados no ensino elementar, dar os primeiros passos no mundo adulto. A narrativa se inicia em espanhol, centrando a câmera com um olhar intimista de plano médio na criança, em seu olhar e em ações distantes do cotidiano apresentado em sua escola. Nesta, conseguimos identificar que está ocorrendo um dia de festa de formatura, a cerimônia de entrega de Diplomas aos estudantes, do que parece ser o ensino fundamental. Muita empolgação forçada e um apresentador/mestre de cerimônias que a todo momento dignifica e engrandece os símbolos pátrios e o sucesso dos estudantes, que cumpriram esta etapa e agora estão prontos para ingressarem em um novo momento de suas vidas. É patente o desinteresse coletivo pela cerimônia realizada. No momento da entrega do diploma a Evaristo, o menino indígena é agora chamado para comparecer no local que esta sendo feita a festividade. A pessoa responsável pela entrega, que se supõe, ser uma autoridade da escola, pergunta a ele onde está seu irmão Tony que não veio pegar o diploma. Ele diz não saber e se responsabiliza em entregá-lo. $\mathrm{Na}$ sequência, entre danças que aparentam serem folclóricas e em meio a aplausos pouco animadores, vemos Evaristo sair do local. Corta para um ambiente onde Evaristo está só. Vemos ele dobrar e guardar o diploma dentro de um livro de Espanhol, sozinho em um quarto, com câmera de plano de conjunto. Com esse gesto simbólico no filme, verificamos um corte na língua até então falada, e isto será emblemático no encerramento desse idioma neste momento do filme. Talvez este plano signifique a preparação para a entrada no mundo indígena, não impregnado com a ótica dos criollos (ou mestiços). Evaristo coloca tudo na mochila e se dirige à cerca de proteção da escola, que lembra a de uma prisão, pois ela se apresenta toda gradeada e as crianças e adultos dentro não parecem estar muito felizes, passando por baixo de um buraco, que podemos ler ou interpretar como a passagem entre estes dois mundos. Na sequência ele se encontra com mais duas crianças, numa montanha onde ao longe vemos muitas árvores e uma bela paisagem, planos de tomadas externas próximas da natureza. Estas crianças também com fenótipos indígenas ao que parece estão brincando, quando o foco da câmera recai e se centra sobre um deles, que é exatamente Tony, o irmão do Evaristo que não fora buscar o diploma. Evaristo fala algo para o grupo e em seguida pega a mochila com tudo que tem dentro e joga em um penhasco (inclusive o tão "incensado" diploma), onde ela acaba ficando presa em um galho de uma árvore. A partir daí o diretor nos leva a acompanhar a vida destes meninos, deixando-nos atentos a um olhar construído ao estilo filmado com câmera na mão. Neste a imagem tremida, deixa-nos a sensação da insegurança na busca de Evaristo e Tony Lerma Batista, no contexto de um mundo adulto que nos vai sendo desvelado como o mundo interior da reserva indígena, onde vivem os dois irmãos e seus parentes. Eles recebem então do pai a missão de levar remédios ao seu tio que está doente e que se encontra no outro lado da reserva. Para isso acabam indo com o cavalo do avô, seu bem mais precioso. Tony pede ao avô o cavalo da família, mas ele nega. O menino decide levar o cavalo assim mesmo. No caminho, erram o percurso e se deparam com um cânion, onde é impossível prosseguir com o cavalo. Eles amarram o animal na árvore e seguem adiante, quando voltam para 
buscá-lo, ele não está mais lá. O animal escapa e os dois irmãos tentam a todo o custo recuperá-lo, perseguindo-o por onde encontram pistas e perguntando a todos se o viram. Nesta caminhada na busca por recuperar o cavalo, vai sendo explicitado o cotidiano dos dois irmãos, seus encontros e desencontros com velhos, mulheres, homens e outras crianças que vivem nesse espaço de liberdade e que constitui a complexa paisagem natural e social do Vale do Okochocci na Serra mexicana de Tarahumara ${ }^{10}$. Todas os personagens desde o momento do filme em que Evaristo guarda seu diploma passam a falar o idioma nativo Raramuri, inclusive os programas de rádios e suas programações musicais não são feitas em espanhol e sim em Raramuri, língua desta comunidade indígena que luta em sua sobrevivência cotidiana para manter vivas, sua língua, cultura, crenças e tradições. O filme nos descreve nessa busca e nos acontecimentos que vão se fazendo, o frescor das brincadeiras e jogos compartilhados com os outros meninos indígenas, envolvendo-nos em situações que nos levam a arrepios de emoção frente às possibilidades de acidentes, que vão sendo enfrentados por eles nos locais onde transitam com os cavalos. Os cavalos aparecem e são mostrados como representando a própria imagem da masculinidade e poder, força, liberdade e a relação dos homens entre si com os animais e seus espíritos ancestrais. O contexto coletivo é dado através da representação do aperto de mãos a todos, em todo momento, reiterando a ideia de communitas, que Victor Turner (2008) ao lidar com o México de Hidalgo apresenta como característica deste povo reafirmando a força do campo social e político destes atores na arena societária, enquanto uma forma de contra poder e expressão simbólica da experiência social que torna visíveis suas crenças e ideias comunitárias.

A imagem que aparece identificando os indígenas no filme e os diferencia dos não índios, para além de sua fisionomia fenotípica, como um sinal diacrítico é a de todos usando sandálias de couro no mesmo feitio. Por outro lado, no filme, existe uma narrativa sobre a família e as relações familiares, onde diferentemente da ocidental dominante, ela aparece formada por relações ampliadas, onde todos são parentes e estabelecem relações de reciprocidade entre si, aparentando outro modelo de família. No filme não aparecem os conflitos e as diferenças internas. Contrapondo-se à nossa ideia de cuidado paterno/materno, ela se estende para uma comunidade de iguais nos cuidados e responsabilidades para com as crianças, mais ampla e fluída do que a do modelo da família ocidental hegemônica, comunicando a ideia de um pertencimento igualitário de um todo que se contrapõe ao individualismo ocidental. Caminhando, Evaristo e seu irmão Tony aparentemente em vários momentos chegam nas fronteiras da reserva e voltam, nos passando a ideia de superação de si e de seus limites, momentos onde a câmera fixa sua imagem e nos passa a impressão de uma possível segurança, pois esta reserva diferentemente da escola é um espaço que dominam. Agora voltando com a imagem da câmera na mão tremida como se fosse o personagem a caminhar e travellings da paisagem fixos com planos alongados e sem cortes, onde o filme alterna as imagens entre um clima de documentário e de filme de ficção e ao mesmo tempo registrando a vida cotidiana do grupo sob o olhar das crianças, ampliando e engrandecendo em muito a ficção. Além disso, a inexistência de cenários fechados e produzidos, e em sua quase maioria externos - fato de que lança mão recorrentemente o

10 Cabe ressaltar que Turner em seu artigo clássico sobre o México, coloca esta região entre mais apenas quatro outras como as únicas que ainda em 1800 não teria ocorrido a "diluição do indianismo puro" (TURNER, 2008: 128). 
diretor - sublinha o valor da autenticidade. Pelo olhar construído dos meninos sobre o mundo o filme acaba colocando em evidência as próprias dúvidas subjetivas dos meninos sobre o seu estar no mundo. Em um momento da trajetória dos dois irmãos aparece um homem que fala espanhol e dá carona a eles juntamente a uma mulher, que aparenta ser parente deles. Este mesmo homem aparece em uma festa, embebedando os indígenas, para nessa situação "negociar" com eles os cavalos e as suas mulheres, enquanto os dois irmãos ainda continuam a procura do cavalo perdido. Depois de muito andar e refletir sobre si com brincadeiras e cenas mais pausadas e reflexivas em função do encontro e conversas com os parentes que há muito aparentemente não viam, pois moravam do outro lado da reserva, percurso que raramente era feito por eles, finaliza com a entrega dos remédios. Assim os dois irmãos, retornam ao local do penhasco que haviam passado na saída da escola e aparecem jogando pedras juntos, na tentativa de derrubar a mochila que havia ficado presa na árvore. Com ela em mãos, Evaristo abre o livro de espanhol, já não mais em um espaço aberto, e tira de dentro dele de forma titubeante o diploma, umedecido pelas intempéries do tempo, por ter provavelmente ficado ao relento, quando na árvore. Um corte do plano e temos a redefinição do espaço externo à reserva para o da escola, onde vemos o menino voltar pelo buraco da cerca. Mais um corte agora para outro plano externo, onde ele e seu amigo aparecem no pátio de um outro colégio maior brincando com outras crianças e vestidos com o uniforme de uma escola secundária. Corta mais uma vez para dentro de uma sala de aula onde entra um professor que se apresenta falando em espanhol e começa a fazer uma chamada dos estudantes presentes. Os dois primeiros estudantes confirmam sua presença e o terceiro nome é repetido várias vezes, ocorrendo neste momento outro corte para a face em expressão de dúvida de Evaristo que finalmente responde depois de algum tempo titubeante, confirmando sua presença. Corte então para o lado externo onde vemos Tony o outro irmão sair por uma porta do colégio para o que parece ser um momento prévio de brincadeiras com mais dois amigos, contrapondo a dúvida entre a confirmação da identificação que não é fácil na sala de aula com a direta pelo lúdico das brincadeiras entre crianças.

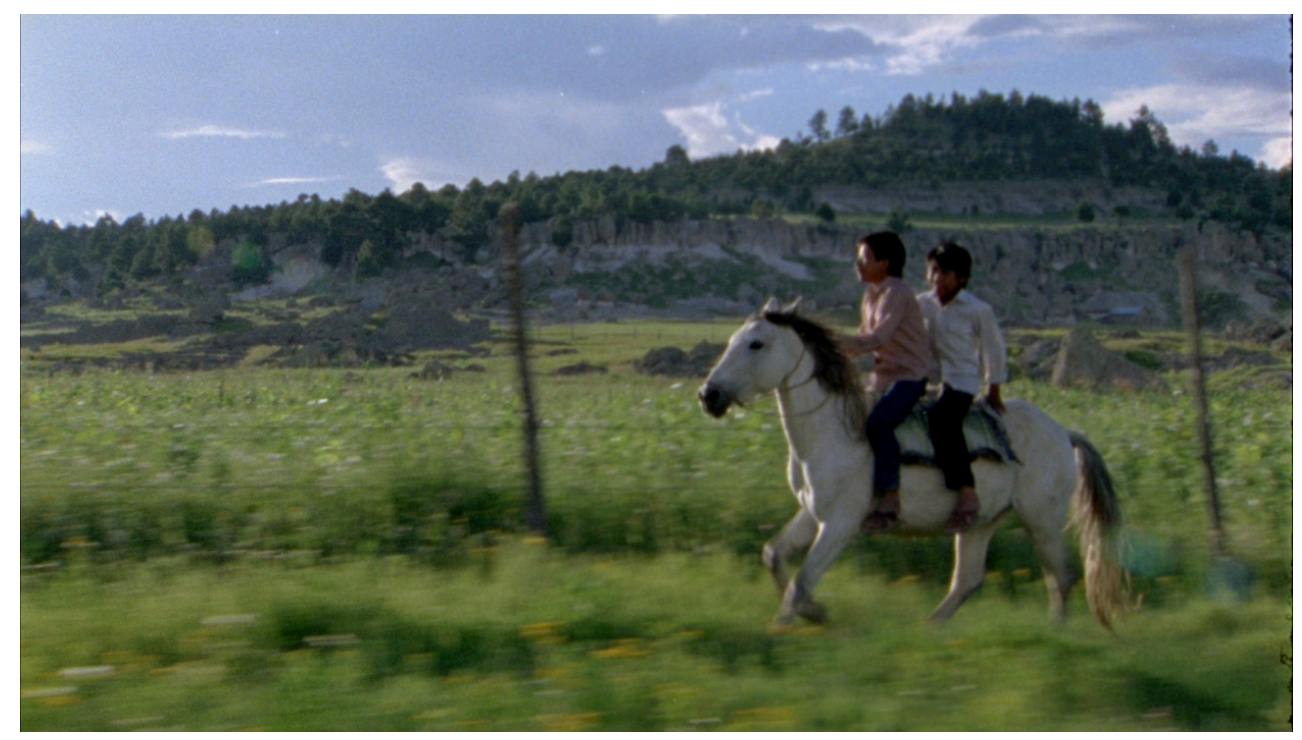




\section{Mundos em conflito: arte e guerra}

O segundo filme, El Violin, se inicia com uma cena violenta de tortura, um corpo sangrando em duas cores visto por trás com o torturado de costas e alguns soldados a lhe agredir, tendo ao fundo outros prisioneiros olhando. No interrogatório agressivo percebemos uma busca constante por alguém. Em cena posterior uma das prisioneiras esta sendo estuprada pelo soldado que a interroga exigindo a revelação do local onde estaria o elemento procurado. $\mathrm{O}$ filme nos traz a vida de uma família indígena, aparecendo inicialmente na sequência na cidade, para ganhar dinheiro com o patriarca Hidalgo tocando violino, seu filho violão e o neto pedindo dinheiro em pagamento das músicas tradicionais cantadas em pé para as pessoas sentadas em restaurantes e bares da cidade. Mostra-nos a dura realidade que eles enfrentam ao terem que passar uma noite na mesma. Enquanto avô e neto dormem, o filho vai a um bar em busca de algo que em um primeiro momento não fica claro, mulher e diversão talvez?!... Mas não, no fundo estava à procura de armas e para quê?

No caminho de volta e já distantes da cidade no dia seguinte ao que parece depois de uma noite de sono, os três estão na boleia do caminhão (pegando carona com mais outras pessoas), o filho recebe dinheiro de uma das mulheres em uma atitude que reforça a inquietação do expectador. Quando estão caminhando na trilha que dá para a aldeia, várias mulheres em fuga correm desesperadas. $\mathrm{O}$ filho de Hidalgo pergunta então sobre sua mulher às outras que vem fugindo e elas dizem que os soldados a pegaram. Nesse momento percebemos que a mulher que havia sido estuprada no início do filme provavelmente era a mulher dele. Ele diz ao avô e ao filho para irem com as mulheres e em seguida se esgueira rastejando até um local onde pode ver os homens da aldeia ajoelhados, com os soldados perfilados os ameaçando com armas pelas costas e perguntando onde está o líder. Aí identificamos que o líder é ele. Um policial atira na direção dele e pede ajuda aos outros para persegui-lo. Ele sai correndo rastejando... e escapa da perseguição. A narrativa se desenvolve mostrando-o se rastejando em plano geral e em contracampo a ação do Exército em seu encalço. Nisso a imagem se escurece e fecha-se em cortes rápidos e sons dentro da mata, ele a adentra e depois de uma longa caminhada que nos traz o desespero a partir dos cortes rápidos e câmera focada no ator em plano americano, chega em uma clareira, onde se encontra com um grupo de guerrilheiros e guerrilheiras em seu acampamento. Abrindo o diafragma e a imagem da câmera em um travelling panorâmico sobre o acampamento junto a um rio, foca a imagem voltando aonde ele se encontra aflito perguntando a um guerrilheiro onde está o comandante e depois indo falar com ele, descrevendo o que houve na aldeia e se preparando com os outros para reagir. Na sequência, após um corte com fusão vemos o velho avô buscar meios para comprar armas, não conseguindo, ele vai com seu burrico - onde a granulação da imagem se aprofunda pelo escurecimento dos contrastes do movimento - para o povoado tentar passar para ver se consegue reaver algo. Até aí ficamos sem compreender o porque desta dificuldade, mas o fato é que o bloqueio dos militares no meio da estrada, mostrado posteriormente em flashback, impede os guerrilheiros de terem acesso a suas munições que foram enterradas em um milharal vizinho a aldeia. Nesse processo Hidalgo com seu burrico é barrado e apreendem seu violino. $\mathrm{O}$ comandante da operação aparece e a imagem em close dele se alterna com a de Dom Hidalgo, o comandante pede que ele toque. A partir daí o 
comandante vai tentar tocar e não conseguindo, pede para Hidalgo que o ensine. $\mathrm{O}$ velho, com a promessa que vai ensinar ao comandante, consegue passar pelo bloqueio com o violino. Aos planos rápidos do anterior embate e tensão se alternam poucos cortes e imagens que nos passam a tranquilidade posterior, até chegar ao milharal e as munições. Ele faz isso várias vezes e a sua relação com o comandante se aprofunda, explicitando as carências sentimentais e dilemas existenciais do militar. O comandante decide mandar, que nos é mostrado através de diálogos e imagens paralelas, um dos soldados acompanhar o que o velho iria fazer do outro lado da barreira. Numa caixa enterrada o soldado o vê pegar munição e deixar o violino, aí fica explícito que o velho estava passando a munição pros guerrilheiros dentro da caixa do violino. Ele pega Hidalgo em flagrante e o comandante descobre que o velho estava suprindo com munição os guerrilheiros. Com o violino na mão ele pede ao velho para tocar e Hidalgo fala que não vai tocar, "que se acabou a música". Ouvimos um tiro. Volta a cena os sons de tortura do início do filme. É feito então um corte mostrando agora o neto/garoto cantando nos bares da cidade, falando sobre a resistência e luta por tempos melhores do povo verdadeiro, ajudado por uma menina que o acompanha, pedindo moedas. Importante ressaltar que o diretor afirmou em entrevista posterior ao filme ter se valido de recursos tais como a utilização do preto-e-branco para que o grupo de guerrilheiros que é retratado no filme parecesse mais amplo que o Exército Zapatista de Libertação Nacional-EZLN11, possibilitando com isso retratar outros tempos e espaços onde pessoas vivenciam e sofrem situações similares de conflito e violência. Que a situação do filme não é a de uma única região, mas se repete, caracterizando a situação dos indígenas em toda América Latina. Nas palavras do diretor:

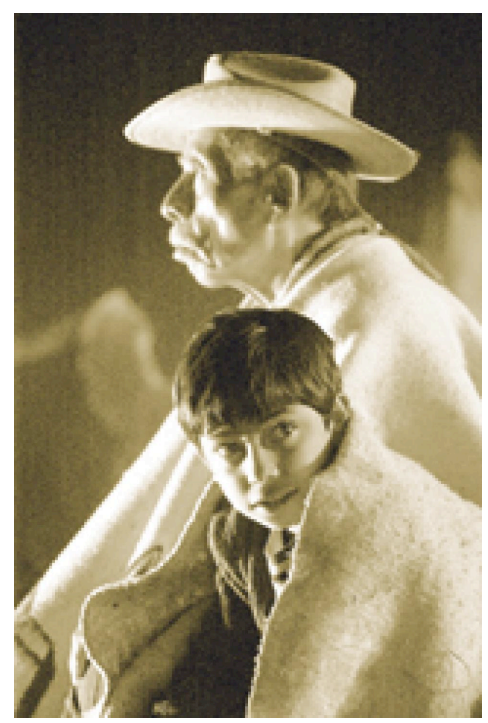

[...] Es un tema que habla de una realidad no resuelta, no solo en México sino en muchos países de América Latina. Es un tema que no se ha tocado nunca en una solo película mexicana. Se ha tocado en muchos documentales, pero La gente ve poco documental. [...] Mucha gente me ha dicho aquí: se fuera en color la distribuimos de otra manera". Pero no es en color porque este tema es difícil. Hablar de este tema es complicado. Hay un movimiento armado, el EZLN que en algún momento causó mucha euforia. En México, ya se oído mucho de esto. A lo que yo me refiero es que hay un poco de cansancio de la gente. Por eso hablar de esto es complicado y siegue siendo mui complejo, es un problema de 500 años. Ahora esta ese movimiento, pero en México ha habido muchos movimientos armados. Hay toda una historia recurrente de La guerrilla. En México el sistema había logrado que esto no se supiera. [...] Yo decía se hacemos una película que exprese un tiempo y un espacio determinado, es muy fácil desprender-se de ella. Pero eso pasa en México y en América Latina, antes de ayer y pasado mañana. Ése es uno de los planteamientos y una de las aspiraciones de la película. Qué tiene que ver eso con el blanco y negro y la camera en mano? Se trata de que sea un documental, ésa es la propuesta. [...] Porque con el blanco y negro puede parecer que estás viendo algo que de verdad sucedió, que no es una historia construida, aun que sabes es una ficción. [...] [La película] habla de una realidad que es muy particular, pero está tocando cosas con la que podemos identificarnos. En este sentido creo que no aplica nacionalidad. (AMANCIO, 2012: 74-75) ${ }^{12}$

\footnotetext{
${ }^{11}$ O Exército Zapatista de Libertação Nacional (EZLN) é uma organização armada mexicana de caráter político-militar e composição majoritariamente indígena. Sua inspiração política principal é o anarquismo, corrente de Emiliano Zapata e Ricardo Flores Magón, sua estratégia militar é a guerrilha e seu objetivo criar as Comunidades Autônomas Indígenas". (Justificar nota de rodapé e manter padronização).

${ }_{12}$ Disponível em: http://www.cinelatino.com.fr/fr/festival/2007/scolaires/telechrgements/elviolin.doc. Acesso em: 20 fev. 2012
} 


\section{O tempo e seus espelhos}

O terceiro filme Corazón del tiempo, retrata indígenas no México de hoje e nos conta a história de três gerações de herdeiros dos Mayas, hoje indígenas e camponeses da Selva Lacandona, vivendo no Sudeste Mexicano. Diferentemente do último filme que utiliza a estratégia da imprecisão para uma possível generalização da problemática por toda a América Latina e a identificação com as muitas realidades indígenas que ainda resistem a seu brutal processo de expropriação, este filme nos leva a conhecer o cotidiano de trabalho e vida nas hoje Comunidades Autônomas Zapatistas. Liberadas da tutela do "Mau Governo"13 do Estado Mexicano e coordenadas pelas juntas do "Bom Governo", que congregam as comunidades indígenas, os apoiadores civis e os insurgentes que conformam o EZLN. Sonia é no início do filme prometida ${ }^{14}$ (pedida) em casamento em troca de uma vaca, proposta pelo pai do companheiro Miguel, explicitando-se as relações tradicionais de laços familiares e as associações de compadrio e parentela, focando o dote e as relações de aliança dele advindas. Porém no decorrer do filme ela se apaixona por Júlio, um zapatista rebelde insurgente que vive nas Florestas das Montanhas. Paralelo a isso a avó de Sônia, Zoraida conta à sua outra neta mais nova Alícia como foi seu casamento e consequentemente nos descreve a vida que viveu em contraposição a hoje "segura" vida que tem em função da "grande família". Momentos chaves do filme são apresentados pelos diálogos, que definem criticamente os papéis e as relações da comunidade com a Igreja, assim como as estabelecidas pelos latifundiários que expropriaram as terras e as riquezas indígenas. Em um deles Zoraida, a avó, esta falando sobre seu casamento e a ordem dada a ela pelo padre "podre" para se arrepender dos seus pecados para poder se casar e o absurdo que isto implicava para a racionalidade deles a tal ponto que a neta ri da postura do padre e da religião. Zoraida diz também que quando se casou tudo foi muito diferente, pois a precariedade deles era tão grande que só se lembra de ter passado muita fome e se casado porque amava seu avô. O amor de Sonia por Júlio coloca em risco a ordem da comunidade e em função disso é convocada uma Assembleia para coletivamente se resolver o problema. A mesma desenvolve o argumento do direito aos jovens de hoje em função do novo momento revolucionário, em que se reveem as antigas tradições e principalmente a necessidade de igualar o direito de escolha entre os sexos, sobre suas relações presentes e das coletivas no futuro. Isso se daria depois de devolvida a vaca e paga uma medida compensatória para a família de Miguel em café e outra em milho. Desta Assembleia participa toda a comunidade zapatista, incluindo as crianças, os observadores legais estrangeiros e os insurgentes. Para completar a situação no meio do imbróglio aparece também o Exército inimigo mexicano que suspende as discussões e coloca todos a barrar o avanço dos militares invasores. O filme termina com Sônia indo viver e lutar junto a Júlio nas Montanhas. Cabe ressaltar a atuação de atores que foram treinados entre os jovens das comunidades em luta e a ótima engenharia de som presente na seleção de músicas, grande parte conformada pela que se ouve e produz nas próprias comunidades zapatistas. A compreensão da importância dos corridos e das músicas nativas para os zapatistas evocando sua origem e comunidade nos permite uma narrativa paralela excepcional.

${ }_{13}$ Denominação que os rebeldes zapatistas dão ao Governo do Estado Mexicano.

14 Forma tradicional de pedido de casamento entre o povo chiapaneco, herdeiros dos Mayas. 
O filme coloca em discussão as relações amorosas, face à tradição e o contexto familiar evidenciando as imposições colocadas pelos seus opressores que introduzem uma lógica estranha à da tradição vivida. $\mathrm{O}$ papel tradicional das mulheres e as relações de gênero são reavaliados no momento revolucionário atual. Um tema fundamental que é o do direito à escolha amorosa em detrimento da tradição, com um predomínio do que poderíamos chamar no filme um amor por escolha que ameaça a estabilidade da comunidade. O diferencial é que isto é encarado como um problema coletivo e não individual, a ponto de ser discutido numa Assembleia por toda comunidade. Nesta assembleia se apresentam cada um dos personagens, a mulher apaixonada, o homem com o dote humilhado, o miliciano zapatista amado, a comandante zapatista, os pais da noiva e do noivo e suas razões. Um dos elementos que merece destaque nesta reunião é o fato que Sônia quase deixa Júlio por ele não se pronunciar e explicitar sua posição sobre a relação amorosa dos dois, ao que este contrapõe o seu amor como opção.

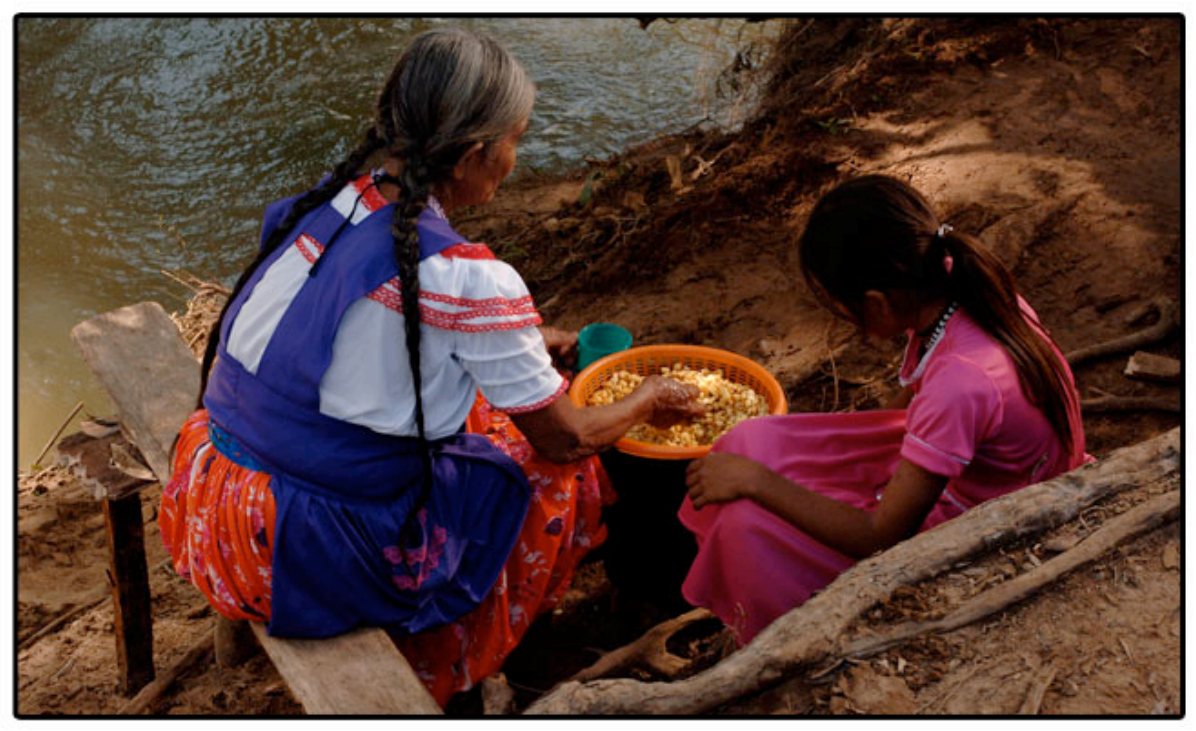

\section{Tempos e espaços do viver}

Se em Cochochi vemos o elo das relações familiares e das tradições sendo vividas com uma naturalidade ímpar pelas crianças e adultos da reserva indígena onde vivem, $E l$ Violín retrata esta relação da passagem das tradições orais e nelas as narrativas de resistência do avô (que posteriormente é morto) e de seus ancestrais míticos e imaginários ao neto que finda cantando este estilo de música popular mexicano, os corridos pelas ruas da cidade em troca de moedas.

No momento que estão no meio da mata, Dom Plutarco conta para Lúcio, seu neto, porque estão longe de sua mãe e irmã e as razões pelas quais existe luta e até quando ela irá. Na primeira parte desta narrativa fílmica temos uma decupagem clássica, formada por planos e contraplanos, variando entre o médio e o primeiro, alternados com gerais, para ambientar melhor a história e localizar espacialmente o público. Este é seguido por um enorme plano sequência que mergulha na natureza, paralelamente enquanto é contada uma lenda pelo avô da origem dos "Homens verdadeiros", que começaram a lutar contra os 
gananciosos pelas terras, que seriam suas porque tinham sido deixadas pelos seus avós para os seus filhos e os filhos dos seus filhos. Saindo da terra a câmera acompanha o tronco de uma árvore e ao mesmo tempo o som do violino do avô tocando recomeça, passando pelas folhas da árvore até chegar a uma magnífica Lua cheia.

Em Corazón del tiempo temos a tripla personagem composta pela temporalidade passada vivida ou memorial pela narrativa musical da neta, a mulher e sua avó (lembrando os clássicos filmes de Jorge Sanginés, que consegue criar personagens múltiplos pois estes seriam mais próximo da realidade indígena) onde quem sabe não seriam a mesma pessoa se alternando na luta pela sobrevivência, ontem, hoje e sempre... Os vários planos que mostram os reflexos da neta, a se ver no rio ou nos seus mergulhos, nos remetem ao tempo dos espelhos e aos seus reflexos, que na cosmologia Maya, nos reiteram tempos e espaços míticos e atuais do drama social.

Podemos pensar que a vida social como drama possibilita recuperar o sentido das interligações entre o extraordinário e ordinário na vida social. $\mathrm{Na}$ formulação de Victor Turner (CICARONE, 2004: 83) os dramas sociais são formas processuais que constituem os desafios perpétuos a todas as aspirações de perfeição da organização social e política, introduzindo uma ruptura no consenso coletivo das normas sociais, seguida de um estado de crise e tentativas de compensação e resolução. Essa visão resgata a dimensão criativa como processo de transformação dos conflitos e de recriação da tradição, reintroduzindo na cena a textura da vida social e os atores como sujeitos em ação e interação, insurgindo-se dessa forma contra as leituras dos sistemas culturais, que fornecem uma imagem homogênea da sociedade estudada, reificando as condutas humanas e inviabilizando o acesso à forma processual de produção da vida social. O drama social na visão do autor seria um processo marcado por valores e sentimentos, e o repertório de estratégias e mecanismos aos quais as sociedades recorrem para superar as crises, incluindo os rituais de reparação e compensação, representando aqueles instrumentos através dos quais os grupos tentariam se examinar, se representar, se compreender e por isso agir sobre si mesmo.

\section{Em busca de uma conclusão ainda que provisória}

Crianças, Homens e Mulheres seriam palavras que poderiam nos ser muito diretas, mas que com precisão poderiam também se adequar na descrição dos principais personagens e conflitos de cada um dos três filmes. Fundamentalmente os filmes analisados refletem sobre as relações da cultura e sociedade indígena frente ao Estado através das suas mise-en-scènes, configuradas na presença e caracterização dos exércitos nacionais como vilões nos dois últimos filmes e pela escola, seus tempos e projetos políticos disciplinares no primeiro. As crianças rarámuri participam de uma sociedade muito específica como se pode ver a partir da seguinte descrição etnográfica feita por Ángel Acuña Delgado ${ }^{15}$ em seu artigo Aproximasión a la kinésica de los rarámuri:

La sociedad rarámuri no constituye un sistema del todo coherente, exento de contradicciones, no apreciamos una visión del mundo, de la existencia, que sea colectivamente homogénea, la enorme cantidad de particularidades pone de

${ }_{15}$ Disponível em: http://www.dimensionantropologica.inah.gob.mx/?p=4638. Acesso em 15 fev. 2013. 


\begin{abstract}
manifiesto la heterogeneidad, la diversidad en sus respuestas culturales en su manera de ser y estar en el mundo; aunque todo ello dentro de un esquema común que los vincula como pueblo y les da un sentido de identidad altamente arraigado, todo ello se aprecia en lo corporal. En el cuerpo se percibe las huellas del proceso de cambio cultural, las consecuencias del choque o contactos con otras culturas. En tal sentido es de destacar la resistencia que históricamente han mantenido al cambio en muchos aspectos, y las transformaciones que han experimentado aquellos elementos adoptados de fuera a los que se le han dado un espacio en la propia cultura, siendo revitalizados con sentido práctico. De acuerdo con el modelo presentado por Bonfil Batalla, al conjugar la procedencia de los elementos culturales con los ámbitos de control o decisión, en la sociedad rarámuri que reside en la Tarahumara abunda la "cultura autóctona" y la "cultura apropiada" en mayor medida que la "cultura enajenada" y la "cultura impuesta", como consecuencia de no haber perdido su capacidad para tomar decisiones propias.
\end{abstract}

La nota predominante en la corporeidad rarámuri es la "heterogeneidad de comportamientos" que se presentan en el interior del grupo étnico, heterogeneidad que refleja un modo de vida independiente en donde la libertad de acción es su principal atributo..."

Contraposto a isto temos as relações de solidariedade e o reconhecimento dos outros como familiares extensos, parentes ou a denominação abreviada de companheiro insurgente ou rebelde nos compas incessantemente falados entre os indígenas que se colocam no filme e na realidade como herdeiros dos Mayas presentes no Corazón del tiempo. As "palavras verdadeiras" segundo os zapatistas, são aquelas que "caminham" tendo seu sentido sempre ressignificado e conseguem chegar "direto ao coração". Independente de sua conotação histórica, elas se reconfiguram e continuam atuais surgindo no filme incessantemente nas expressões coletivas "Zapata presente, Zapata presente, La lucha siegue!", ou seja, dando força aos momentos de enfrentamento. As palavras que caminham ${ }^{16}$ aparecem também representadas nas ideias presentes

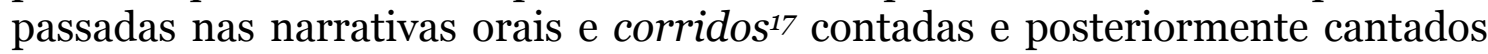
nas ruas em trocas de moedas, tanto pelo avô Hidalgo, quanto por seu neto. Este sobrevivente e novo resistente na "luta semiótica", alterando os sentidos das narrativas visuais e mentais na reafirmação das visões subjetivas dos mundos indígenas na arena do drama social ou na reconfiguração do espaço da communitas. Aparece também na vida das crianças que independente das cobranças para se normatizarem pela escola bilíngue dos brancos, conseguem compartilhar as brincadeiras e códigos de sociabilidade infantil, pertinentes as suas culturas ligadas ao convívio direto da natureza e com seus amigos indígenas. Ou seja, a busca de autonomia e do direito à diferença é uma constante, e se expressa na ideia de "mudar o mundo sem tomar o poder"18 que é na prática muitas vezes tolhida pelo Estado e suas instituições. O direito humano básico de serem eles próprios e viverem de acordo com sua autonomia frente aos agenciamentos e disciplinamentos normatizadores das diferenças, lhes é negado, que os leva a criar novas estratégias criativas de resistência.

\footnotetext{
${ }^{16}$ Palavras como Igualdade, Fraternidade e Liberdade, que são tanto das consígnias zapatistas quanto da Revolução Francesa, porém no contexto de Chiapas são remetidos a realidade dos dias de hoje e reatualizadas, assim tendo o seu sentido ressignificado. Isto é feito pelos próprios zapatistas que estabelecem esta consígnia também como sua, só que a atualizam para o seu contexto específico e a realidade de lutas que enfrentem no sul do México, em Chiapas.

${ }_{17}$ Música popular mexicana.

18 Ideia e palavra chave presente nas comunidades e mobilizações zapatistas, alguns a remetem ao Subcomandante Insurgente Marcos, mas dizem que ele não existe, e que na verdade seria um personagem criado para explicitar as palavras e pensamentos das comunidades em luta.
} 


\section{Referências}

AMANCIO, Tunico e TEDESCO, Marina Cavalcanti. Brasil - México: aproximações cinematográficas. Niterói, Editora da UFF, 2011.

AVELLAR, José Carlos. A Ponte Clandestina. São Paulo, Ed. 34, 1995.

BAJO, María Dolores Fuentes e MURILLO, María Dolores Pérez. A memória filmada: América Latina através de seu cinema - o cinema como fonte para a história e recurso pedagógico no ensino da história da América. Saeculum Revista de História, $\mathrm{n}^{\mathrm{o}}$ 19. João Pessoa, UFPB, 2008. Disponível em: http://periodicos.ufpb.br/ojs2/index.php/srh/article/view/11412/6526. Acesso em: 30 de maio de 2015 .

CAMINAS, Alfredo. La construcción de personajes. Perpectiva general. CÓLON, Pedro Sangro e FLORIANO, Miguel Á. Huerta. El personaje em El cine - Del papel a La pantalla. Madrid, Calamar, 2007.

CICARONE, Celeste. Drama e sensibilidade: migração, xamanismo e mulheres mbyá. Revista de Indias, vol. LXIV, núm. 230, p. 81-96, 2004. Disponível em: http://revistadeindias.revistas.csic.es/index.php/revistadeindias/article/viewFi le/412/480. Acesso em: 30 de maio de 2015.

DELGADO, Ángel Acuña. Aproximación a la kinésica de los rarámur. Dimensión Antropológica, vol. 48, enero-abril, pp. 7-41, 2010. Disponível em: http://www.dimensionantropologica.inah.gob.mx/?p=4638. Acesso em: 30 de maio de 2015.

DURAND, Gilbert. $L$ imagination symbolique. $2^{\text {a }}$ ed. Paris, Col. Quadrige, PUF-Presses Universitaires de France, 1964.

Entrevista com Diego Luna. Festival de Cinema do Rio de Janeiro. RJ, 2007. Disponível em: http://festivaldorio.com.br/site/index.php?option=com_content\&task=view\&i $\mathrm{d}=283 \&$ Itemid $=98$. Acesso em: 30 de maio de 2013.

FRANCHETTO, Bruna (org.) Dossiê Mulheres Indígenas. Revista Estudos Feministas, 7 (1). Florianópolis, UFSC. 1999.

HIKIJI, Rose Satiko. Imagem-violência. Mimesis e reflexividade em alguns filmes recentes. Dissertação (Programa de Pós-graduação em Antropologia Social - Faculdade de Filosofia, Letras e Ciências Humanas, Universidade de São Paulo, São Paulo, 1998.

JABLONSKA, Aleksandra Z. Cristales Del tiempo: pasado e identidad de las películas mexicanas contemporáneas. México, Universidad Pedagógica Nacional, 2009.

Identidades en redefinición: los procesos interculturales en el cine mexicano contemporáneo. In: Estudios sobre las Culturas Contemporáneas. Época II. Vol. XIII. Núm. 26, p. 47-76, 2007. Disponível em: 
http://www.culturascontemporaneas.com/contenidos/identidades_en_redefini cion.pdf. Acesso em: 07 de fevereiro de 2015.

LASMAR, Cristiane. Mulheres Indígenas: Representações In: FRANCHETTO, Bruna (org.) Dossiê Mulheres Indígenas. Revista Estudos Feministas, 7 (1). Florianópolis: PPGAS/UFSC. 1999. Disponível em: http://www.journal.ufsc.br/index.php/ref/article/viewFile/11989/11264.

Acesso em: 07 de dezembro de 2014.

MARIN, Louis. De la representation. Paris, Gallimard-Le Seuil, col. Hautes études, 1994.

MORIN, Edgar. Le cinéma ou l'homme imaginaire. Paris, L'Edition de Minuit, 1995 [1956].

. O Cinema ou o Homem Imaginário. Lisboa: Moraes Editora, 1980.

MURILLO, María Dolores Pérez e FERNÁNDEZ, David Fernández. La memoria filmada: América Latina a través de su cine. Madrid, Iepala, 2002

NUÑEZ, Fabián. Entrevista de Jorge Sanjines. Rio de Janeiro, 13 de agosto de 2004. Disponível em: www.contracampo.he.com.br. Acesso em: 9 de maio de 2015 .

SANGINÉS, Jorge y Grupo Ukamu. Teoría y Práctica de un Cine junto al Pueblo. México, Siglo Veintiuno Editores, 1979.

SCHUMANN, Peter B. Historia del cine latinoamericano. Buenos Aires, Legasa, 1987.

SHOHAT, ElIa. Notes on the "post-colonial”. Social Text, 31-32, p.99-113, 1992.

SHOHAT, Ella e STAM, Robert. Crítica da imagem eurocêntrica: multiculturalismo e representação. São Paulo, Cosac Naify, 2006.

SILVA, Juliano Gonçalves da. O Indio no Cinema Brasileiro e o espelho recente. Dissertação (Programa de Pós-Graduação em Multimeios - Instituto de Artes, Universidade Estadual de Campinas. Campinas, 2002.

- Iracema, uma transa amazônica. Cadernos de Antropologia e Imagem - A imagem do Índio no Brasil. Rio de Janeiro, Uerj, n.12(1), p.169-181, 2001.

- Entre o bom e o mau selvagem: ficção e alteridade no cinema brasileiro. In: Espaço Ameríndio. UFRGS, v.1, p.195 - 211, 2007. Disponível em: http://www.seer.ufrgs.br/index.php/EspacoAmerindio. Acesso em: 30 de maio de 2015 .

Filmes indígenas latino americanos: um paradigma em construção?. In: PAIVA, Samuel; CÁNEPA, Laura; SOUZA, Gustavo. (Org.). Estudos de cinema e audiovisual - Socine. $1^{\text {a }}$ ed. São Paulo, Socine, v., p. 59-73, 2010. Disponível 
http://www.socine.org.br/livro/XI_ESTUDOS_SOCINE_b.pdf. Acesso em: 30 de maio de 2015 .

TURNER, Victor. Hidalgo: A História enquanto Drama Social. Dramas, Campos e Metáforas - ação simbólica na sociedade humana. Niterói, UFF, 2008.

WARMAN, Arturo. Los indios mexicanos em el umbral del milenio. Mexico, FCE, 2003. 